\title{
Using the Pillars of Infection Prevention to Build an Effective Program for Reducing the Transmission of Emerging and Reemerging Infections
}

\author{
Westyn Branch-Elliman ${ }^{1,2} \cdot$ Connie Savor Price ${ }^{2,3} \cdot$ Mary T. Bessesen ${ }^{1,2} \cdot$ Trish M. Perl $^{4}$
}

Published online: 1 July 2015

(C) Springer International Publishing AG 2015

\begin{abstract}
Preventing transmission of emerging infectious diseases remains a challenge for infection prevention and occupational safety programs. The recent Ebola and measles outbreaks highlight the need for pre-epidemic planning, early identification, and appropriate isolation of infected individuals and health care personnel protection. To optimally allocate limited infection control resources, careful consideration of major modes of transmission, the relative infectiousness of the agent, and severity of the pathogen-specific disease are considered. A framework to strategically approach pathogens proposed for health care settings includes generic principles (1) elimination of potential exposure, (2) implementation of administrative controls, (3) facilitation of engineering and environmental controls, and (4) protection of the health care worker and patient using hand hygiene and personal protective equipment. Additional considerations are pre-epidemic vaccination and incremental costs and benefits of infection prevention interventions. Here, major strategies for preventing health-care-associated transmissions are reviewed, including
\end{abstract}

This article is part of the Topical Collection on Global Environmental Health and Sustainability

Westyn Branch-Elliman

westyn.branch-elliman@ucdenver.edu

1 Department of Medicine, Division of Infectious Diseases, Eastern Colorado VA Healthcare System, Denver, CO, USA

2 Department of Medicine, Division of Infectious Diseases, University of Colorado School of Medicine, Denver, CO, USA

3 Department of Medicine, Division of Infectious Diseases, Denver Health and Hospital, Denver, CO, USA

4 Department of Medicine, Division of Infectious Diseases, Johns Hopkins University, School of Medicine, Baltimore, MD, USA reducing exposure; vaccination; administrative, engineering, and environmental controls; and personal protective equipment. Examples from recent outbreaks are used to highlight key infection prevention aspects and controversies.

Keywords Infection prevention and control · Transmission · Basic reproductive number $\cdot$ Health-care-associated infections · Emerging and reemerging infections . Environmental controls

\section{Introduction: Health Care Settings as the "Perfect Storm"}

Person-to-person transmission of infectious agents primarily occurs by three distinct modes. These include (1) contact, direct or indirect, with skin, mucus membranes, or a contaminated fomite; (2) droplet, in which large droplets spread in distances of 3 to $6 \mathrm{ft}$ through coughing; and (3) aerosol, where smaller "aerosol" droplets have prolonged environmental persistence and the potential to travel relatively long distances. Some pathogens, such as respiratory syncytial virus (RSV) and influenza, take advantage of multiple different modes of transmission.

Several features of health care settings promote the sometimes dramatic transmission of contagious infectious diseases. These include congregation of sick, infectious, and at-risk patients; stretched and sometimes inadequate physical resources; a culture of "presenteeism," where health care personnel work while symptomatic and contagious; and variable compliance with infection prevention practices. These elements interact to create a "perfect storm" for person-toperson transmission of infectious agents. Health care personnel working on the frontlines are at particularly high risk of infection when exposed to certain infectious diseases, such as 
Ebola, severe acute respiratory syndrome coronavirus (SARS$\mathrm{CoV}$ ), and Middle East respiratory syndrome coronavirus (MERS-CoV), in part because the signs and symptoms can be non-specific, hospitalized patients with these infections may be particularly infectious, and health care personnel perform procedures that may aerosolize organisms.

Infection prevention programs are used to battle this "perfect storm" with multifaceted interventions. To effectively reduce spread, prevention programs must consider several issues, including mode of transmission, efficiency of transmission, severity of the infection, effectiveness of prevention strategies, effectiveness of treatments, and probability of exposure to other patients and health care personnel. Allocation of limited resources also comes into play.

Here, we will review how to evaluate different pathogens including emerging and reemerging infections in terms of severity of illness and epidemic potential and discuss strategies for their control within health care settings, using a framework based on four central pillars: (1) elimination of potential exposure, (2) implementation of administrative controls, (3) facilitation of engineering and environmental controls, and (4) protection of the health care worker and patient using hand hygiene and personal protective equipment [1,2]. Additional considerations are pre-epidemic vaccination and incremental costs and benefits of infection prevention interventions.

\section{Epidemic Potential and the Role of Vaccination}

The epidemic potential of a pathogen is always a consideration when planning infection prevention responses. One way to measure the epidemic potential of a particular pathogen is through its basic reproductive number or $R_{0}$. The $R_{0}$ represents the average number of individuals who will contract an infection from one person in a fully susceptible population and is primarily determined by the infectivity of the pathogen. Higher $R_{0}$ estimates represent more efficient transmission (Fig. 1). If the $R_{0}$ is 1 , then the pathogen will not infect

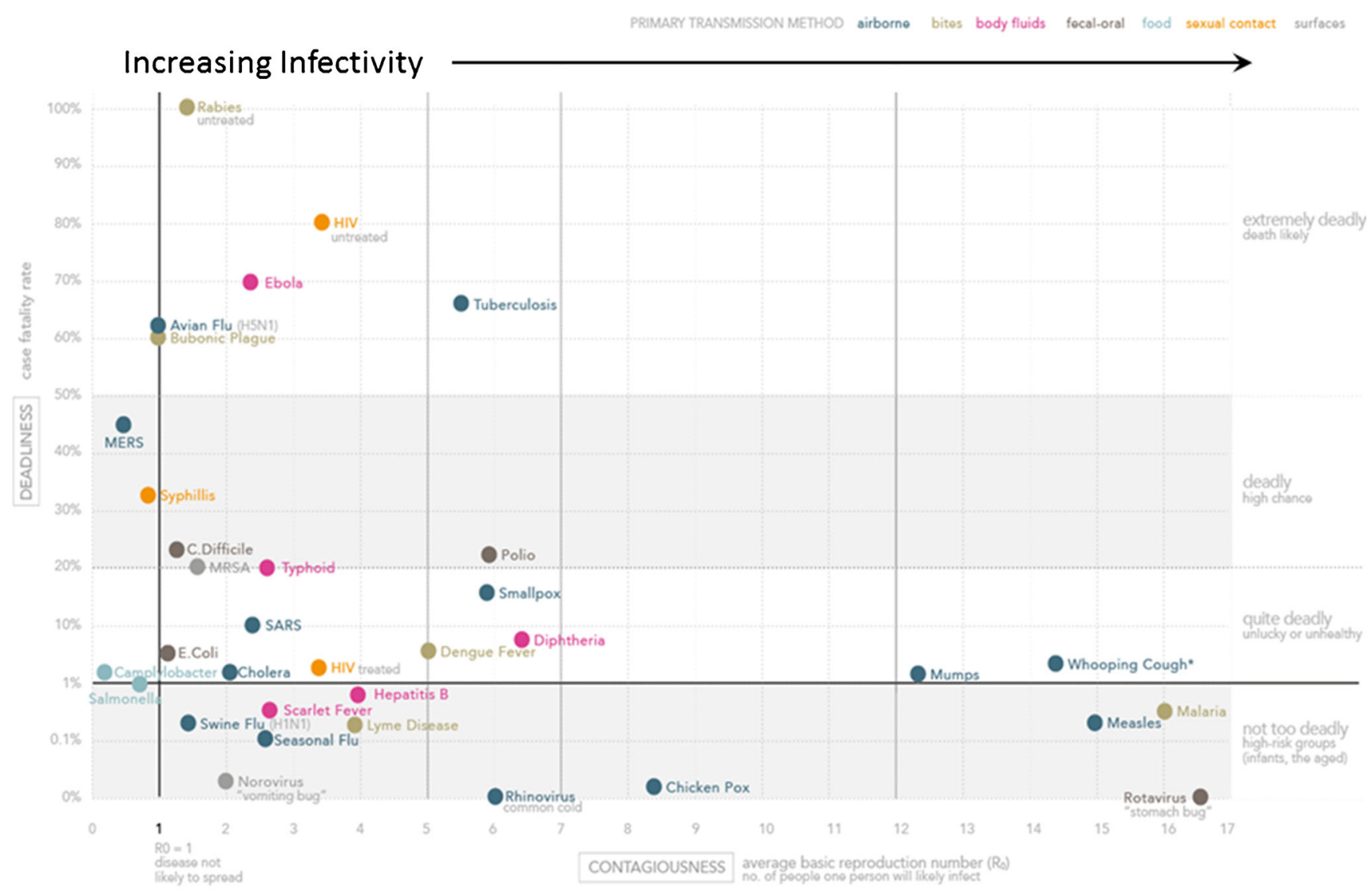

Fig. 1 "Contagiousness" versus mortality rate of selected human pathogens. The basic reproductive number compared to the case fatality rate of many infectious agents ("contagiousness"). In general, organisms that are more infectious and more deadly merit more infection prevention resources and attention than those that are less infectious and less deadly.
Key examples highlighted here include Ebola, SARS-CoV, measles, and rotavirus. The figure is courtesy of David McCandless of "Information is Beautiful" (available at http://www.informationisbeautiful.net) and is reproduced with permission. Minor modifications (to the title and axis) were made for the purposes of this publication 
enough people to propagate through the population. Conversely, organisms with $R_{0} 1$ have the potential to cause epidemics.

Once so common as to be considered a guarantee in life, much like "death and taxes," [3] measles has an $R_{0}$ of 12-18, indicating high person-to-person transmissibility. Smallpox has an $R_{0}$ between 3.5 and 6 [4], and the $R_{0}$ of the 1918 influenza strain is 2-3 [5]. Conversely, the $R_{0}$ of MERS$\mathrm{CoV}$ is estimated as 0.7 [6]. These numbers help explain, in part, why influenza and measles have the potential to cause worldwide pandemics, while MERS-CoV caused only small clusters of illness. In the most recent outbreak, the $R_{0}$ of Ebola virus is estimated to be between 1.5 (in Guinea) and 2.0 (in Sierra Leone) [7••], although some analyses suggest an $R_{0}$ as high as 2.5 [8]. All of these estimates suggest that persistent transmission of Ebola virus will occur if authorities do not implement effective strategies to interrupt transmission.

Other variables that affect epidemic potential of a pathogen include the duration of pathogen shedding and the proportion of the population susceptible to the organism. Some interventions, such as the use of valacyclovir for chronic herpes simplex infection [9] or oseltamivir treatment for influenza infection [10], reduce the duration of shedding and may be used to mitigate transmission and spread. However, for the most part, duration of shedding is difficult to impact with readily available interventions.

Population susceptibility may be reduced through public health vaccination campaigns and/or natural immunity for some infectious agents. Vaccination is very effective for controlling several infections of historical importance, including smallpox, measles, and polio. Until recently, the epidemic potential of measles has been low because the vast majority of the population has been non-susceptible due to effective vaccination programs. Natural infection can also provide protection from repeated infections: In the case of measles, natural infection induces life-long protection. For other pathogens, such as norovirus, natural infection may only provide limited, short-term protection.

Vaccines can be used to protect a population from an epidemic through two mechanisms. "Herd protection" and "herd immunity" are two connected but separate processes used to describe methods to contain transmission [11]. Herd protection occurs when a large proportion of the population is immune to an infectious agent and there are inadequate numbers of susceptible hosts to propagate the infection and cause an epidemic. Herd protection does not protect a nonimmune individual from disease if exposed to an infected individual. However, if the proportion of susceptible individuals in a population is very low, a large outbreak will not occur because the disease does not have the opportunity to propagate. In other words, herd protection safeguards the population but not the individual. Herd immunity occurs when live virus vaccines are used to induce immunity and these live virus vaccines are able to spread throughout the population, typically by the fecal-oral route, to infect unvaccinated individuals. When exposed to the live virus vaccine, unvaccinated individuals often develop immunity. Thus, herd immunity may protect $b o t h$ the individual and the population. Examples of vaccines that provide both herd protection and herd immunity are the oral polio vaccine and the oral rotavirus vaccine. Conversely, the inactivated polio vaccine provides herd protection only. Some vaccines, such as the rabies vaccine, do not confer either type of population-based protection [11].

The proportion of the population that must be immune to a particular pathogen in order to gain herd protection is inversely proportional to the $R_{0}$ of the agent [12]. Thus, both the infectivity of the pathogen and the effectiveness of the vaccine come into play when determining what proportion of the population must be vaccinated to achieve herd protection. For example, assuming an $R_{0}$ of $18,94 \%$ of the population must be immune to measles to achieve herd protection. The effectiveness of a single dose of measles vaccine is approximately $95 \%$ [13]. Some individuals - including very young children and the immunosuppressed - are not eligible to receive vaccination. Thus, because the vaccine is not perfect, nearly $100 \%$ of the population eligible to be immunized must be vaccinated in order to prevent measles epidemics from taking hold.

The importance of herd protection and public health measures is underscored by a recent multistate outbreak of measles [14]. In this cluster, voluntary drops in vaccination in pockets of the population created an opening for an epidemic. In some parts of California, vaccination rates are lower than in developing countries and far lower than rates necessary to obtain herd protection [15]. In the outbreak, which started at Disneyland outside of Los Angeles, 55 \% (28/52) of individuals infected were unvaccinated, an additional $31 \%(17 / 52)$ had an unknown vaccination status, and $4 \%(2 / 52)$ were undervaccinated [14].

\section{Mode of Transmission}

Another key consideration is mode of transmission. Table 1 summarizes several key pathogens and their primary means of spread. Infection prevention programs implement basic processes that impact many pathogens and are hence considered horizontal in nature. Hand hygiene, cleaning and disinfection, and surveillance for epidemiologically significant organisms or syndromes are strategies that impact the continuum of organisms and mitigate their transmission.

However, infection prevention programs must implement interventions for specific pathogens targeted at their transmission path, especially when they are difficult to treat, particularly virulent, or highly transmissible (Fig. 1). For example, norovirus, a highly infectious gastrointestinal virus, spreads through the contact-based route and persists in the 
Table 1 Summary of key pathogens, basic reproductive number, major modes of transmission, and targeted prevention measures

\begin{tabular}{|c|c|c|c|}
\hline Pathogen & $R_{0}$ & Mode(s) of transmission & Targeted prevention measures \\
\hline Measles (rubeola) [16] & $12-18$ & Airborne & $\begin{array}{l}\text { Vaccination, early identification, airborne isolation, } \\
\text { contact tracing, and quarantine }\end{array}$ \\
\hline Chickenpox (varicella) & $9-10$ & Airborne and contact with blisters & $\begin{array}{l}\text { Vaccination, early identification, airborne and contact } \\
\text { isolation, and avoid contact with rash }\end{array}$ \\
\hline Influenza [5] & $2-3$ & $\begin{array}{l}\text { Large droplet, indirect contact, trans- } \\
\text { ocular, and possible small droplet }\end{array}$ & $\begin{array}{l}\text { Droplet precautions, enhanced environmental cleaning, } \\
\text { and vaccination }\end{array}$ \\
\hline Norovirus [17] & $3-4$ & Direct and indirect contact & $\begin{array}{l}\text { Contact precautions, enhanced environmental cleaning, and } \\
\text { gloves for food service employees }\end{array}$ \\
\hline Pertussis (Bordetella) & $12-17$ & Droplet & Vaccination, droplet isolation, and postexposure prophylaxis \\
\hline SARS-CoV [6] & $<1$ & $\begin{array}{l}\text { Droplet, direct, and indirect contact, } \\
\text { airborne not entirely excluded, associated } \\
\text { with aerosol-generating procedures [18] }\end{array}$ & Contact and airborne isolation [18] \\
\hline MERS-CoV [6] & $<1$ & $\begin{array}{l}\text { Droplet, direct and indirect contact, airborne } \\
\text { not entirely excluded (may be associated } \\
\text { with aerosol-generating procedures) }\end{array}$ & Contact and airborne isolation \\
\hline Ebola $[7 \bullet \bullet, 8]$ & $1.5-2.5$ & $\begin{array}{l}\text { Direct and indirect contact with contaminated } \\
\text { bodily fluids, possible sexual transmission }\end{array}$ & $\begin{array}{l}\text { Contact precautions, enhanced personal protective equipment, } \\
\text { environmental cleaning, and proper burial practices }\end{array}$ \\
\hline Mumps & $4-7$ & Droplet, direct, and indirect contact & Vaccination and droplet precautions \\
\hline Polio & $5-7$ & Direct and indirect contact & Vaccination and enhanced environmental cleaning \\
\hline Smallpox & $5-7$ & Airborne and contact & Vaccination and airborne and contact isolation \\
\hline Tuberculosis $[19]^{\mathrm{a}}$ & 1 & Airborne & $\begin{array}{l}\text { Airborne isolation and screening of contacts including health } \\
\text { care personnel }\end{array}$ \\
\hline Tuberculosis $[20]^{\mathrm{b}}$ & 3.55 & Airborne & $\begin{array}{l}\text { Airborne isolation, screening of contacts including health care } \\
\text { personnel, control of HIV, and treatment of latent infections }\end{array}$ \\
\hline $\operatorname{MRSA}[21]^{\mathrm{c}}$ & $0.3-0.5$ & Contact & $\begin{array}{l}\text { Contact precautions, enhanced environmental cleaning, consider } \\
\text { decolonization, and use of chlorhexidine in certain settings }\end{array}$ \\
\hline C. difficile $\left[22^{\mathrm{c}}\right]$ & $0.55-2$ & Contact & $\begin{array}{l}\text { Contact precautions, soap and water hand hygiene, antimicrobial } \\
\text { stewardship, enhanced environmental cleaning, and attempted } \\
\text { elimination of spores from the environment }\end{array}$ \\
\hline
\end{tabular}

${ }^{a}$ In HIV-negative patients

${ }^{\mathrm{b}}$ In HIV-positive patients

${ }^{\mathrm{c}}$ In health care settings

environment for prolonged periods of time [23]. Thus, during norovirus outbreaks, infection prevention strategies are targeted at hand hygiene, contact isolation, and specialized environmental cleaning [24]. Mycobacterium tuberculosis spreads through small-droplet aerosols; thus, prevention programs focus on respirators for personal protection, as well as environmental controls (including hospital ventilation systems) to prevent spread. Other pathogens, such as RSV, take advantage of multiple different modes of transmission; RSV is well documented to spread both by large droplets and via contact with contaminated surfaces, followed by self-inoculation. Thus, both droplet and contact precautions are recommended to mitigate spread $[25,26]$.

The mode of transmission of a pathogen may also vary with clinical circumstances. Pathogens that typically spread via large droplets, such as influenza and SARS CoV, may be aerosolized in certain high-risk circumstances. Thus, special consideration must be given to aerosol-generating procedures, which may place health care personnel at particularly high risk of infection and require higher levels of personal protection [27].

\section{Developing an Infection Prevention Response: The Four Pillars}

A hierarchy of controls has been outlined by the CDC for prevention of transmission of influenza in health care settings and is generally applicable to other transmissible pathogens. These principles include (1) eliminating potential exposure, (2) administrative controls, (3) engineering and environmental controls, and (4) personal protective equipment [1]. These four fundamental pillars of infection prevention, coupled with cost-benefit analysis, can be applied to other infectious agents when considering an approach to a specific pathogen and a general prevention program. 


\section{The First Pillar: Early Detection and Prevention of Exposure}

The first cornerstone in preventing and containing infections is case detection, which prompts implementation of appropriate precautions in a timely fashion and prevents exposure in susceptible hosts [1]. Case identification starts outside of a given health care facility, with public health campaigns and media attention that increase awareness of a circulating infection. These public health interventions assist in case detection by bringing a particular problem to into the public eye.

Within a health care facility, early detection of many infections requires preemptive strategies before diagnostic tests are obtained, such as identifying "syndromes," or constellations of symptoms, that are suggestive of a particular illness. For example, Ebola screening and detection include questioning about travel to affected areas, followed by screening for key symptoms, such as fever. Flagged cases signal the need for a test, isolation, and/or certain administrative controls. Suspicion of disease that is sufficient to prompt clinicians to order a diagnostic test may then prompt further actions, including isolation, cohorting of patients with similar syndromes and/or confirmed infection, and notification of infection prevention or the laboratory.

The critical importance of early identification is underscored by the transmission of Ebola virus to two health care personnel in Dallas [28], after the identification of the first Ebola case diagnosed in the USA [29]. The index patient initially presented to an emergency room but was discharged home after crucial information regarding his exposure and travel history was not reviewed [30]. If the patient had been identified as potentially having Ebola during his initial presentation, the ultimate outcome of this case may have been different.

\section{The Second Pillar: Administrative Controls}

Administrative controls are policies and procedures designed to prevent and reduce exposure and transmission of organisms within a health care facility. For administrative controls to be maximally effective, health care personnel at all levels must maintain a high level of awareness for potential threats in order to identify communicable or pathogenic infectious diseases. Once identified, infection prevention interventions may be tailored to the specific pathogen. Examples of policies and practices include mandating influenza vaccination among all health care personnel, requiring education of health care personnel around certain practices, and implementing syndromic screening in high-risk areas including the emergency departments, using isolation and barrier precautions and appropriate triage of potential cases [1].

\section{The Third Pillar: Engineering and Environmental Controls}

\section{Engineering Controls}

In 1955, Wells noted that "Airborne epidemics are absent from an ecologic population provided with adequate air hygiene;" this tenet holds true in medical centers today [31]. Patient placement in airborne isolation rooms is a strategy employed in developed countries to prevent transmission of airborne pathogens, such as M. tuberculosis, measles, or Varicella zoster [32]. In the USA, airborne isolation rooms must meet minimum requirements for air exchanges per hour, and negative pressure must be maintained in the room, relative to surrounding areas [33]. Other engineering controls include wholebuilding ventilation and use of HEPA filters. The ultimate purpose of these controls is to first dilute the concentration of airborne pathogens and second to prevent the movement of potentially infectious particles throughout the facility [34].

Traditional engineering strategies have focused on ventilation systems; however, novel strategies to promote air quality may also be considered, particularly in resource-limited settings. For example, in one study comparing "old-fashioned" hospitals, designed with natural ventilation including open doors and large, open windows, to "modern hospitals," with mechanically ventilated negative pressure rooms, opening doors and windows was found to have more than double the number of air exchanges per hour than was achieved by mechanical ventilation [35]. Furthermore, an infection risk model found that patients placed in the older, naturally ventilated rooms were at significantly lower risk of tuberculosis acquisition following exposure when compared to patients placed in mechanically ventilated rooms [35]. These findings are being translated into clinical practice in some resource-limited settings. Haiti recently christened two open-air hospitals, taking advantage of sunlight and island breezes to reduce transmission of respiratory pathogens, including tuberculosis [36]. If this low-cost architecture is found to be effective, it may be used as a blueprint in other countries and settings.

\section{Environmental Controls}

The environment, including water supply systems, may be a source of pathogens causing sporadic or epidemic disease and thus is an important target for administrative controls. A dramatic example of an environmental outbreak is the cluster of pneumonia that occurred after a national convention of the American Legion in 1976 [37]. The cause of the cluster was ultimately found to be Legionella pneumophila, which contaminated the water in cooling towers serving the convention hotel. Outbreaks and isolated cases of Legionella continue to occur in health care settings and are commonly linked to water sources [38, 39]. Given the ubiquitous nature of this organism, 
protecting hospital inpatients or the general population from L. pneumophila with filtering facepiece respirators (i.e., using personal protective equipment) is not a feasible prevention strategy. So, rather than targeting individuals, mitigation efforts have focused on making health care facilities inhospitable to L. pneumophila growth in water systems by maintaining temperatures that are not conducive to growth of the organism or by adding to the water oxidants such as chlorine dioxide, copper, or silver [40].

Environmental persistence is another important consideration for reducing health-care-associated transmissions. MERS-CoV may persist in the environment for up to 2 days [41]. Calciviruses, including noroviruses, are resistant to standard disinfectants and can be transferred from the environment to food for at least 7 days [42], highlighting the importance of cleaning and disinfection to prevent propagation. Attention to detail, the type and duration of cleaning, and the cleaning agent can enhance removal of pathogens from the environment. In some instances, the use of environmental disinfection has been promoted and shown to decrease transmission of multidrug-resistant organisms and Clostridium difficile $[43,44]$.

\section{The Fourth Pillar: Hand Hygiene and Personal Protective Equipment (PPE)}

\section{Hand Hygiene}

Encouraging excellent hand hygiene practices is a central tenet of all infection prevention programs, given the low cost and high effectiveness of this strategy. Many infectious agents, such as vancomycin-resistant enterococcus, respiratory viruses, and $C$. difficile, contaminate health care worker hands following contact with an infected or colonized patient or their environment $[45,46]$. Improving hand hygiene compliance clearly reduces the incidence of health-care-associated infections $[47,48]$. Thus, hand hygiene campaigns are an important consideration in any program targeting healthcare-associated transmissions.

\section{Gowns and Gloves}

For pathogens that are transmitted by the contact route, such as methicillin-resistant Staphylococcus aureus (MRSA), vancomycin-resistant Enterococcus (VRE), and C. difficile, gowns and gloves are commonly used interventions designed to interrupt propagation. These interventions are based on clinical evidence demonstrating frequent health care personnel contamination following interaction with patients colonized or infected with multidrug-resistant organisms [46, 49].

However, data regarding the effectiveness of gowning and gloving for preventing the spread of multidrug-resistant organisms are mixed. One large cluster-randomized study examining universal use of gowns and gloves versus usual care in the intensive care unit found no reduction in their primary outcome of MRSA or VRE but did find reduced MRSA acquisition in the group with universal gloving [50 ]. Another investigation found a lower incidence of health-careassociated infections during a period of gown and glove use when compared to a period with glove use alone [51]. Further complicating the picture is clinical evidence suggesting that placing a large proportion of patients in contact isolation may lead to unintended consequences, including fewer health care personnel visits and increased incidence of depression, and may be associated with decreased compliance with other infection prevention measures, including hand hygiene. Thus, overuse of this strategy may paradoxically increase the incidence of health-care-associated infections and worsen clinical outcomes [52•, 53, 54]. In sum, although somewhat controversial, targeted gowning and gloving to prevent the transmission of select multidrug-resistant organisms remain common clinical practices.

\section{Respirators and Medical Masks}

The respirator was initially developed to protect the wearer from the outside. Conversely, the medical mask was designed to protect the outside from the wearer [55]. Medical masks are used to prevent acquisition of pathogens that transmit via large droplets, which are $\geq 5 \mu$ in diameter, fall rapidly to the ground with gravity, and generally remain contained within the upper respiratory tract, rather than being inhaled deep into the lungs [56]. Respirators are used to prevent inhalation and transmission of aerosols, which are considerably smaller, linger in the air for prolonged periods of time, and may be inhaled into the alveoli and deep lung tissue.

Several types of respirators are used to combat transmission of infectious agents. The simplest and least expensive types are particulate respirators, such as the N95 respirator [57]. The chemical cartridge/gas mask respirator filters out gases and sometimes particles from inhaled air; the effectiveness of the mask for reducing exposure is dependent upon the type of filter used in the mask [57]. Some filters are designed primarily to remove particles (such as biological warfare agents) and others to remove chemicals. Powered airpurifying respirators (PAPRs) work by using a fan to blow air through a filter and into the hood worn by the user; the same types of filters used for the gas mask respirator may also be used for the PAPR [57]. Of note, some PAPRs are designed to provide additional levels of protection, including eye coverage and skin coverage, and thus may be used to protect against not only droplet and airborne transmissions but also trans-ocular and contact-based transmissions. To obtain a similar level of protection with an N95 device, additional barriers, such as face shields, must be used in addition to the respirator. 
N95 respirators are designed to block at least $95 \%$ of all particles between 0.1 and $0.3 \mu$ and have higher efficiency with larger particles. Among particles $\geq 0.75 \mu$, the filtration capacity in vitro exceeds $99.5 \%$, provided that there is a good facial fit [58]. Medical masks, which are not designed for particle filtration, have lower efficiency. One specific medical mask has $95 \%$ efficiency for filtering particles $\geq 3 \mu$ but there is not a minimum filtration standard for these devices [59]. Thus, medical masks may be effective for preventing exposure to large droplet particles, but not aerosols, which are increasingly noted to play a role in transmission of respiratory viruses [60].

Not all respirators are created equal, and the performance and relative benefit will vary depending upon the specific device chosen. Similarly, medical masks vary widely in their efficacy. A manikin simulation study found that two types of medical masks had markedly different filtration capacity: One allowed $20.5 \%$ of virions to penetrate, while the other allowed $84.5 \%$ [55].

Fit is another factor that may impact performance. In one manikin study, tightly fitting respirators blocked the inhalation of a significantly higher proportion of particles compared to well-fit medical masks; however, poorly fitting respirators performed similarly to medical masks [61]. A "passing" fit factor for respirators was $>100$; tightly fitting respirators achieved a fit factor of $>200$ and tightly fitting medical masks a fit factor of 135 [61]. The loosely fitting respirators and medical masks both had fit factors in the range of 2.3-4.6, well below a "passing" level [61]. The tightly fitted N95 respirators (e.g., 3MM1860) blocked $99.8 \%$ of all viral particles, including $>99.5 \%$ of all aerosols [61]. The tightly fitting medical mask (Kimberly Clark 47625) also demonstrated excellent performance, blocking $94.5 \%$ of all viral particles, including greater than $91.8 \%$ of all aerosols [61]. To simulate real-world use of the respiratory protection devices, the investigators also evaluated loosely fitting medical masks and respirators and found that loosely fitting respirators blocked greater than $69.9 \%$ of viral particles, including almost $60 \%$ of the virus in small particles, and that loosely fitting medical masks blocked $68.9 \%$ of viral particles, including greater than $51.2 \%$ of the virus contained in small particles [61]. These findings may help to explain why, in idealized settings, medical masks appear less effective than respirators, but significant differences have not been demonstrated in clinical implementation trials.

Another factor affecting the relative performance of medical masks versus respirators is the somewhat arbitrary construct of "large" versus "small" droplet transmission. In the real world, exhaled droplet size occurs over a spectrum. Lindsley et al. detected influenza viral RNA in cough samples of students and found that only $35 \%$ of the influenza RNA was contained in particles $>4 \mu$ in diameter - the usual size of "large droplets" [62]. Forty-two percent of the viral RNA was contained in particles less than $1 \mu$ in diameter and $23 \%$ in an intermediate size range [62].

Variation in real-world use of the devices also affects performance. The devices must fit the facial contours of the face and must be worn at all times when in contact with the patient or the potentially contaminated environment. Health care personnel compliance with these respiratory protection devices is often low [63], in part because the devices are perceived as interfering with the clinician-patient relationship and can cause facial rashes and respirators can be very uncomfortable when worn for prolonged periods.

Although several clinical trials have been designed to evaluate the optional respiratory protection device, differences in devices used, clinical end points, and compliance come together to muddy interpretation.

\section{Source Control}

Common practice is to place patients suspected to have respiratory viruses in masks and then to isolate them from other patients. A recent study by Johnson et al. evaluated this method of "source control" and found that medical masks and respirators are equally effective for this purpose, although the study was underpowered to detect a small difference in effectiveness [64]. These clinical results are supported by in vitro data demonstrating that both medical masks and respirators reduce the dispersion distances of exhaled air [65]. Interestingly, N95 respirators were found to significantly reduce forward dispersion distance when compared to medical masks, but substantial sideways air leakage occurred with both devices [65].

\section{Historical Context}

In 1990, following outbreaks of health-care-associated tuberculosis, including multidrug-resistant tuberculosis in the USA [66], the CDC recommended substituting dust-mist particulate respirators for simple isolation masks in tuberculosis isolation rooms. They reasoned that air leaks around the simple masks could result in a higher rate of purified protein derivative skin-test conversion, although clinical data are not available to support this rationale [67]. In 1993, a new draft guideline proposed that high-efficiency particulate respirators be used instead of dust-mist particulate respirators. These recommendations were based upon filtration efficacy and on the observation that a single tubercle bacillus can cause disease. The guideline was heavily criticized at the time, as being both impractical and ineffective [68]. Published clinical outcome data are still not available to support the recommendation.

During the SARS-CoV pandemic in 2003, a similar shift was seen in recommendations for respiratory protection in 
Toronto. In contrast, other countries continued to recommend medical masks for health care personnel protection. Ultimately, transmission was halted based on developing aggressive case finding strategies, implementing administrative and engineering controls and enhancing compliance with hand hygiene and use of personal protective equipment-regardless of which type of respiratory protection device was implemented. Then once again, with the emergence of the H1N1 influenza pandemic in 2009, the CDC tightened recommendations that previously advocated for use of medical masks against influenza to advocate for the use of N95 respirators in the health care setting [2, 69].

Were these recommendations rooted in fear or in science? Perhaps both. While there is some evidence suggesting that N95 respirators may be superior to medical masks for prevention of respiratory viral transmission, clinical data are limited.

During the SARS-CoV pandemic, health care workers who donned no respiratory protection device were at increased risk of acquisition compared to those who used either medical masks or respirators [69]. Results from prospective clinical trials are conflicting and difficult to interpret due to study design and methods. One clusterrandomized controlled trial conducted among nurses in Canada failed to demonstrate a difference in incidence of influenza between nurses who were assigned to wear medical masks versus respirators; however, the study was stopped early due to shifting recommendations during the H1N1 influenza pandemic [70]. A second randomized controlled trial examining medical masks versus continuous or intermittent use of N95 respirators demonstrated a reduction in the primary end point of clinical respiratory illness, which included both infections and non-infectious outcomes, but failed to demonstrate a reduction in key secondary outcomes, including influenza acquisition [71]. The study also did not adjust for critical confounders, including vaccination rates among study participants [72]. A large, randomized controlled trial of medical masks versus respirators among outpatient providers is ongoing, spanning several seasons of influenza pandemics, and may ultimately answer this question, but will not be completed until 2016 [73].

Practical issues may also come into play when choosing a respiratory protection device or elements of personal protective equipment. Although personnel coming into contact with Ebola patients may not require the higher level air filtration provided by PAPRs, health care personnel at Emory reported early fogging of goggles associated with the use of an N95 mask plus eye protection and thus chose to use PAPRs not because they were needed for protection against aerosols but because of practical considerations [74]. Thus, real-world implementation obstacles may require infection prevention programs to override the theoretical minimum barrier for prevention, to develop a platform that is functional at the bedside.

\section{The Hidden Pillars: Cost and Incremental Benefit}

Although some laboratory studies suggest a marginal benefit to respirators over medical masks for prevention of influenza transmission, the effectiveness of one strategy versus another in clinical practice remains uncertain. Infection prevention interventions designed to protect patients and staff and improve care may also have negative consequences that must be accounted for. N95 respirators are hot and uncomfortable, and PAPRs preclude the use of stethoscopes and thus interfere with the medical examination. PAPRs may also scare patients and staff.

In the setting of unclear benefits, questions of cost and incremental effectiveness come into play. Based on current data, the cost of preventing one influenza transmission to health care workers by opting for respirators rather than medical masks may be as high as $\$ 250$ per case of influenza averted or as low as $\$ 62.50$ [75]. In settings with limited resources, the absolute cost of respirators weighed against the incremental benefit may be substantial.

\section{Conclusions}

Prevention of emerging and reemerging infections requires a multifaceted approach, based on early identification and containment; engineering, environmental, and administrative controls; and personal protective equipment. Recent outbreaks of measles and Ebola virus infection reaffirm that the basic tenets of infection prevention form the backbone of supplemental strategies. Early diagnosis, isolation, hand hygiene, and vaccination can prevent transmission of many infections. Allocation of precious infection control resources should be based on the severity and relative infectiousness of the agent.

\section{Compliance with Ethics Guidelines}

Conflict of Interest Westyn Branch-Elliman declares no conflict of interest.

Connie Savor Price, Mary T. Bessesen, and Trish M. Perl are coinvestigators on the RESPECT Trial, which is funded by the US Centers for Disease Control and Prevention and the Veterans Health Administration.

Human and Animal Rights and Informed Consent This article does not contain any studies with human or animal subjects performed by any of the authors. 


\section{References}

Papers of particular interest, published recently, have been highlighted as:

- Of importance

•- Of major importance

1. US Centers for Disease Control and Prevention. Interim guidance on infection control measures for 2009 H1N1 influenza in healthcare settings, including protection of healthcare personnel. 2010; http://www.cdc.gov/h1n1flu/guidelines_infection_control. htm\#f. Accessed 22 Jan 2015.

2. US Centers for Disease Control and Prevention. Prevention strategies for seasonal influenza in healthcare settings. http://www.cdc. gov/flu/professionals/infectioncontrol/healthcaresettings.htm. Accessed 5 June 2014.

3. Babbott Jr FL, Gordon JE. Modern measles. Am J Med Sci. 1954;228(3):334-61.

4. Eichner M, Dietz K. Transmission potential of smallpox: estimates based on detailed data from an outbreak. Am J Epidemiol. 2003;158(2):110-7.

5. Mills CE, Robins JM, Lipsitch M. Transmissibility of 1918 pandemic influenza. Nature. 2004;432(7019):904-6.

6. Breban R, Riou J, Fontanet A. Interhuman transmissibility of Middle East respiratory syndrome coronavirus: estimation of pandemic risk. Lancet. 2013;382(9893):694-9.

7.• WHO Ebola Response Team. Ebola virus disease in West Africathe first 9 months of the epidemic and forward projections. N Engl J Med. 2014;371(16):1481-1495. Thus study provides a thorough description of the epidemiology of the Ebola virus outbreak in West Africa, including estimations of basic reproductive numbers and a projection of the outbreak moving forward without effective interventions.

8. Lewnard JA, Ndeffo Mbah ML, Alfaro-Murillo JA, et al. Dynamics and control of Ebola virus transmission in Montserrado, Liberia: a mathematical modelling analysis. Lancet Infect Dis. 2014;14(12): $1189-95$.

9. Corey L, Wald A, Patel R, et al. Once-daily valacyclovir to reduce the risk of transmission of genital herpes. N Engl J Med. 2004;350(1):11-20.

10. Ling LM, Chow AL, Lye DC, et al. Effects of early oseltamivir therapy on viral shedding in 2009 pandemic influenza A (H1N1) virus infection. Clin Infect Dis. 2010;50(7):963-9.

11. Paul Y. Herd immunity and herd protection. Vaccine. 2004;22(3-4): 301-2.

12. Scherer A, McLean A. Mathematical models of vaccination. $\mathrm{Br}$ Med Bull. 2002;62:187-99.

13. Demicheli V, Rivetti A, Debalini MG, Di Pietrantonj C. Vaccines for measles, mumps and rubella in children. Cochrane Database Syst Rev. 2012;2, CD004407.

14. CDC Health Alert Network. U.S multi-state measles outbreak, December 2014-January 2015. 2015; http://emergency.cdc.gov/ han/han00376.asp. Accessed 27 Jan 2015.

15. Khazan O. Wealth L. A (2014) School's vaccination rates are as low as South Sudan's. The Atlantic.

16. Anderson RM, May RM, Anderson B. Infectious diseases in humans: dynamics and control. Oxford: Oxford University Press; 1992.

17. Vanderpas J, Louis J, Reynders M, Mascart G, Vandenberg O. Mathematical model for the control of nosocomial norovirus. $\mathrm{J}$ Hosp Infect. 2009;71(3):214-22.

18. Siegel JD, Rhinehart E, Jackson M, Chiarello L. 2007 guideline for isolation precautions: preventing transmission of infectious agents in health care settings. Am J Infect Control. 2007;35(10 Suppl 2): S65-S164.
19. Vynnycky E, Fine PE. The long-term dynamics of tuberculosis and other diseases with long serial intervals: implications of and for changing reproduction numbers. Epidemiol Infect. 1998;121(2): 309-24.

20. Long EF, Vaidya NK, Brandeau ML. Controlling co-epidemics: analysis of HIV and tuberculosis infection dynamics. Oper Res. 2008;56(6):1366-81.

21. Cooper BS, Medley GF, Stone SP, et al. Methicillin-resistant Staphylococcus aureus in hospitals and the community: stealth dynamics and control catastrophes. Proc Natl Acad Sci U S A. 2004;101(27):10223-8.

22. Lanzas C, Dubberke ER, Lu Z, Reske KA, Grohn YT. Epidemiological model for Clostridium difficile transmission in healthcare settings. Infect Control Hosp Epidemiol. 2011;32(6): 553-61.

23. Said MA, Perl TM, Sears CL. Healthcare epidemiology: gastrointestinal flu: norovirus in health care and long-term care facilities. Clin Infect Dis. 2008;47(9):1202-8.

24. Weber DJ, Rutala WA, Miller MB, Huslage K, Sickbert-Bennett E. Role of hospital surfaces in the transmission of emerging health care-associated pathogens: norovirus, Clostridium difficile, and Acinetobacter species. Am J Infect Control. 2010;38(5 Suppl 1): S25-33.

25. Goldmann DA. Transmission of viral respiratory infections in the home. Pediatr Infect Dis J. 2000;19(10 Suppl):S97-S102.

26. Hall CB. Nosocomial respiratory syncytial virus infections: the "cold war" has not ended. Clin Infect Dis. 2000;31(2):590-6.

27. Thompson KA, Pappachan JV, Bennett AM, et al. Influenza aerosols in UK hospitals during the H1N1 (2009) pandemic-the risk of aerosol generation during medical procedures. PLoS One. 2013;8(2), e56278.

28. Fernandez M. Dallas nurse contracts Ebola virus, elevating response and anxiety. New York Times 2014 October 13.

29. Onishi N. U.S. patient aided pregnant Liberian, then took Ill. New York Times 2014 October 1.

30. US Congress. Notable elements of Mr. Duncan's initial emergency room visit. 2014; http://energycommerce.house.gov/sites/ republicans.energycommerce.house.gov/files/Hearings/OI/ 20141016/Timeline2.pdf. Accessed 23 Jan 2015.

31. Wells W. Airborne contagion and air hygiene: an ecological study of droplet infection. Cambridge: Harvard University Press; 1955.

32. Jensen PA, Lambert LA, Iademarco MF, Ridzon R. Guidelines for preventing the transmission of Mycobacterium tuberculosis in health-care settings, 2005. MMWR Recomm Rep. 2005;54(RR17):1-141.

33. US Centers for Disease Control and Prevention. 2007 Guideline for isolation precautions: preventing transmission of infectious agents in healthcare settings. 2007; http://www.cdc.gov/hicpac/2007IP/ 2007ip_part4.html. Accessed 9 Feb 2015.

34. Eames I, Tang JW, Li Y, Wilson P. Airborne transmission of disease in hospitals. J R Soc Interface. 2009;6 Suppl 6:S697-702.

35. Escombe AR, Oeser CC, Gilman RH, et al. Natural ventilation for the prevention of airborne contagion. PLoS medicine. 2007;4(2): e68

36. Kimmelman M. In Haiti, battling disease with open-air clinics. New York Times 2014 December 29.

37. Fraser DW, Tsai TR, Orenstein W, et al. Legionnaires' disease: description of an epidemic of pneumonia. N Engl J Med. 1977;297(22):1189-97.

38. Palmore TN, Stock F, White M, et al. A cluster of cases of nosocomial Legionnaires disease linked to a contaminated hospital decorative water fountain. Infect Control Hosp Epidemiol. 2009;30(8): $764-8$.

39. Haupt TE, Heffernan RT, Kazmierczak JJ, et al. An outbreak of Legionnaires disease associated with a decorative water wall 
fountain in a hospital. Infect Control Hosp Epidemiol. 2012;33(2): 185-91.

40. World Health Organization. Legionella and the prevention of legionellosis. 2007; http://www.who.int/water_sanitation_health/ emerging/Legionella.pdf. Accessed 10 Feb 2015.

41. van Doremalen N, Bushmaker T, Munster VJ. Stability of Middle East respiratory syndrome coronavirus (MERS-CoV) under different environmental conditions. Euro Surveill 2013;18(38).

42. D'Souza DH, Sair A, Williams K, et al. Persistence of caliciviruses on environmental surfaces and their transfer to food. Int $\mathrm{J}$ Food Microbiol. 2006;108(1):84-91.

43. Passaretti CL, Otter JA, Reich NG, et al. An evaluation of environmental decontamination with hydrogen peroxide vapor for reducing the risk of patient acquisition of multidrug-resistant organisms. Clin Infect Dis. 2013;56(1):27-35.

44. Best EL, Parnell P, Thirkell G, et al. Effectiveness of deep cleaning followed by hydrogen peroxide decontamination during high Clostridium difficile infection incidence. J Hosp Infect. 2014;87(1):25-33.

45. Landelle C, Verachten M, Legrand P, Girou E, Barbut F, BrunBuisson C. Contamination of healthcare workers' hands with Clostridium difficile spores after caring for patients with $C$. difficile infection. Infect Control Hosp Epidemiol. 2014;35(1):10-5.

46. Hayden MK, Blom DW, Lyle EA, Moore CG, Weinstein RA. Risk of hand or glove contamination after contact with patients colonized with vancomycin-resistant enterococcus or the colonized patients' environment. Infect Control Hosp Epidemiol. 2008;29(2):149-54.

47. Kirkland KB, Homa KA, Lasky RA, Ptak JA, Taylor EA, Splaine ME. Impact of a hospital-wide hand hygiene initiative on healthcare-associated infections: results of an interrupted time series. BMJ Qual Saf. 2012;21(12):1019-26.

48. Allegranzi B, Pittet D. Role of hand hygiene in healthcareassociated infection prevention. J Hosp Infect. 2009;73(4):305-15.

49. Snyder GM, Thom KA, Furuno JP, et al. Detection of methicillinresistant Staphylococcus aureus and vancomycin-resistant enterococci on the gowns and gloves of healthcare workers. Infect Control Hosp Epidemiol. 2008;29(7):583-9.

50. Harris AD, Pineles L, Belton B, et al. Universal glove and gown use and acquisition of antibiotic-resistant bacteria in the ICU: a randomized trial. JAMA. 2013;310(15):1571-80. This landmark randomized controlled trial evaluates the impact of universal contact precautions on spread of multi-drug resistant organisms, such as methicillin-resistant Staphylococcus aureus (MRSA) throughout the intensive care unit.

51. Bearman GM, Marra AR, Sessler CN, et al. A controlled trial of universal gloving versus contact precautions for preventing the transmission of multidrug-resistant organisms. Am J Infect Control. 2007;35(10):650-5.

52. Dhar S, Marchaim D, Tansek R, et al. Contact precautions: more is not necessarily better. Infect Control Hosp Epidemiol. 2014;35(3): 213-21. This prospective cohort study evaluates how the proportion of patients placed on contact precautions affects compliance with other infection control measures. Compliance with contact precautions falls as the number of patients placed on contact precautions increases.

53. Morgan DJ, Diekema DJ, Sepkowitz K, Perencevich EN. Adverse outcomes associated with contact precautions: a review of the literature. Am J Infect Control. 2009;37(2):85-93.

54. Saint S, Higgins LA, Nallamothu BK, Chenoweth C. Do physicians examine patients in contact isolation less frequently? A brief report. Am J Infect Control. 2003;31(6):354-6.

55. Balazy A, Toivola M, Adhikari A, Sivasubramani SK, Reponen T, Grinshpun SA. Do N95 respirators provide 95\% protection level against airborne viruses, and how adequate are surgical masks? Am J Infect Control. 2006;34(2):51-7.
56. Atkinson J, Chartier Y, Pessoa-Silva CL, Jensen P, Li Y, Seto WH, editors. Natural ventilation for infection control in health-care settings. Geneva: WHO; 2009.

57. CDC. Respirator fact sheet. The National Personal Protective Technology Laboratory 2012; http://www.cdc.gov/niosh/npptl/ topics/respirators/factsheets/respfact.html. Accessed 22 Jan 2015.

58. Qian Y, Willeke K, Grinshpun SA, Donnelly J, Coffey CC. Performance of N95 respirators: filtration efficiency for airborne microbial and inert particles. Am Ind Hyg Assoc J. 1998;59(2):128-32.

59. Li Y, Wong $\mathrm{T}$, Chung $\mathrm{J}$, et al. In vivo protective performance of $\mathrm{N} 95$ respirator and surgical facemask. Am J Ind Med. 2006;49(12): 1056-65.

60. Tellier R. Review of aerosol transmission of influenza A virus. Emerg Infect Dis. 2006;12(11):1657-62.

61. Noti JD, Lindsley WG, Blachere FM, et al. Detection of infectious influenza virus in cough aerosols generated in a simulated patient examination room. Clin Infect Dis. 2012;54(11):1569-77.

62. Lindsley WG, Blachere FM, Thewlis RE, et al. Measurements of airborne influenza virus in aerosol particles from human coughs. PLoS One. 2010;5(11), e15100.

63. Daugherty EL, Perl TM, Needham DM, Rubinson L, Bilderback A, Rand CS. The use of personal protective equipment for control of influenza among critical care clinicians: a survey study. Crit Care Med. 2009;37(4):1210-6.

64. Johnson DF, Druce JD, Birch C, Grayson ML. A quantitative assessment of the efficacy of surgical and N95 masks to filter influenza virus in patients with acute influenza infection. Clin Infect Dis. 2009;49(2):275-7.

65. Hui DS, Chow BK, Chu L, et al. Exhaled air dispersion during coughing with and without wearing a surgical or N95 mask. PLoS One. 2012;7(12), e50845.

66. Wenger PN, Otten J, Breeden A, Orfas D, Beck-Sague CM, Jarvis WR. Control of nosocomial transmission of multidrug-resistant Mycobacterium tuberculosis among healthcare workers and HIVinfected patients. Lancet. 1995;345(8944):235-40.

67. Jernigan JA, Adal KA, Anglim AM, Byers KE, Farr BM. Mycobacterium tuberculosis transmission rates in a sanatorium: implications for new preventive guidelines. Am J Infect Control. 1994;22(6):329-33.

68. Iseman MD. A leap of faith. What can we do to curtail intrainstitutional transmission of tuberculosis? Ann Intern Med. 1992;117(3):251-3.

69. Seto WH, Tsang D, Yung RW, et al. Effectiveness of precautions against droplets and contact in prevention of nosocomial transmission of severe acute respiratory syndrome (SARS). Lancet. 2003;361(9368):1519-20.

70. Loeb M, Dafoe N, Mahony J, et al. Surgical mask vs N95 respirator for preventing influenza among health care workers: a randomized trial. JAMA. 2009;302(17):1865-71.

71. MacIntyre CR, Wang Q, Seale $H$, et al. A randomized clinical trial of three options for N95 respirators and medical masks in health workers. Am J Respir Crit Care Med. 2013;187(9):960-6.

72. Bessesen MT, Savor-Price C, Simberkoff M, Reich NG, Pavia AT, Radonovich LJ. N95 respirators or surgical masks to protect healthcare workers against respiratory infections: are we there yet? Am J Respir Crit Care Med. 2013;187(9):904-5.

73. Trish Perl. The respiratory protection effectiveness clinical trial. 2010; http://clinicaltrials.gov/show/NCT01249625. Accessed 19 May 2014.

74. Isakov A, Jamison A, Miles W, Ribner B. Safe management of patients with serious communicable diseases: recent experience with Ebola virus. Ann Intern Med. 2014;161(11):829-30.

75. Branch-Elliman W, Savor Price C, McGeer A, Perl TM. Protecting the frontline: designing an infection prevention platform for preventing emerging respiratory viral illnesses in healthcare personnel. Infect Control Hosp Epidemiol. 2015;36(3):336-45. 